\title{
Proximate Analysis, Antioxidant Activity, and Antibacterial Activity of Fish Sausages Fortified with Bee Bread Extract
}

\author{
Salma Malihah Mohammad ${ }^{D},{ }^{1}$ Amirun Afiq Badrul Hisham, ${ }^{1}$ Nur Atifa Mustapa, ${ }^{1}$ \\ Kim Wei Chan $\mathbb{D}^{2}{ }^{2}$ and Norhasnida Zawawi $\mathbb{D}^{1,2}$ \\ ${ }^{1}$ Department of Food Science and Technology, Universiti Putra Malaysia, 43400 UPM Serdang, Seri Kembangan, \\ Selangor, Malaysia \\ ${ }^{2}$ Natural Medicines and Product Research Laboratory (NaturMeds), Institute of Bioscience, Universiti Putra Malaysia, Serdang, \\ 43400 UPM Serdang, Seri Kembangan, Selangor, Malaysia
}

Correspondence should be addressed to Norhasnida Zawawi; norhasnida@upm.edu.my

Received 9 December 2020; Revised 8 February 2021; Accepted 10 February 2021; Published 23 February 2021

Academic Editor: Laura Arru

Copyright (c) 2021 Salma Malihah Mohammad et al. This is an open access article distributed under the Creative Commons Attribution License, which permits unrestricted use, distribution, and reproduction in any medium, provided the original work is properly cited.

\begin{abstract}
Bee bread is rich in phenolic compounds and recently has gained attention as a food additive, which provides an alternative use to synthetic preservatives. Therefore, this study aims to analyze the proximate composition and antioxidant and antibacterial activities of fish sausages fortified with Heterotrigona itama bee bread ethanolic (BBE) extract at $0.25,0.5$, and $0.75 \%$ concentrations. Incorporation of BBE in fish sausages significantly increased the carbohydrate level and lowered the moisture content. The highest phenolic and flavonoid content were observed in fish sausages with $0.75 \%$ BBE with $23.46 \pm 1.60 \mathrm{mg}$ GAE/g sample and $8.05 \pm 0.24 \mathrm{mg}$ rutin/g sample, respectively. The antioxidant activity revealed the highest DPPH scavenging activity for $0.75 \%$ BBE fish sausage compared to synthetic additive BHT. After 28 days of frozen storage, lipid oxidation activity of fish sausages with $0.75 \%$ BBE had lower thiobarbituric acid reactive substances (TBARS) value than the negative control, but similar $(p>0.05)$ to BHT. The phenolic compounds and antioxidant activities were significantly reduced $(p<0.05)$ after 28 days of storage. Based on the antibacterial activity, BBE was able to inhibit tested foodborne pathogens, and the addition of BBE in fish sausage showed total plate count below $6 \log _{10} \mathrm{CFU} / \mathrm{g}$ within 6 days of frozen storage. This research demonstrated the BBE efficiency as a natural antioxidant with antibacterial properties in fish sausages.
\end{abstract}

\section{Introduction}

Fish sausage, or locally known as "keropok lekor" is one of the popular fish-based products in Malaysia. It is a traditional snack originated from East Coast Malaysia, highly commercialized among locals to be sold at night stalls, school canteen, and hawker stall because of its appetizing taste and cheap price $[1,2]$. It is made from fish, sago flour, and salt which are kneaded and rolled into cylindrical shape before being boiled. Just like any other fish products, fish sausages are prone to spoilage and microbial contamination such as Pseudomonas, Flavobacterium, Corynebacterium, Lactobacillus, Bacillus, and Micrococcus [1]. Therefore, it is perishable with short shelf life storage [3].
Lipid oxidation is one of the major causes of food spoilage in fish products because fish, such as Indian mackerel (commonly used in making "keropok lekor"), contains high polyunsaturated fatty acids (PUFAs) which are susceptible to oxidation [4]. Fish oxidized during processing, cooking, and storage consequently leads to an end product with a foul smell, unpleasant taste, discoloration with slimy texture, development of toxic substances, and also nutrient loss [5]. To sustain the consumption of fish sausage, especially to increase its global commercialization and marketability, its quality needs to be enhanced [2]. In the food industry, the addition of additives is commonly applied to maintain food quality and prolong its shelf life. However, the uses of synthetic preservatives such as 
TABLE 1: Formulation of fish sausages incorporated with BBE at different concentrations and with synthetic additives.

\begin{tabular}{|c|c|c|c|c|c|}
\hline Ingredient $(\mathrm{g})$ & $0 \%$ (negative control) & $0.25 \%$ & $0.50 \%$ & $0.75 \%$ & Positive control \\
\hline Sago starch & 197.00 & 195.75 & 194.50 & 193.25 & 196.00 \\
\hline Mackerel fish (Rastrelliger kanagurta) & 280 & 280 & 280 & 280 & 280 \\
\hline Salt & 10 & 10 & 10 & 10 & 10 \\
\hline Sugar & 8 & 8 & 8 & 8 & 8 \\
\hline Ice water & 5 & 5 & 5 & 5 & 5 \\
\hline $\mathrm{BBE}^{1}$ & - & 1.25 & 2.50 & 3.75 & - \\
\hline Synthetic additive ${ }^{2}$ & - & - & - & - & 1 \\
\hline Total weight & 500 & 500 & 500 & 500 & 500 \\
\hline
\end{tabular}

${ }^{1}$ Percentage of BBE was based on the substitution with sago starch. ${ }^{2}$ All formulations used potassium sorbate except for antioxidant analysis which used BHT.

butylhydroxyanisole (BHA), butylhydroxytoluene (BHT), tert-butylhydroquinone (TBHQ), and propyl gallate (PG) are strictly controlled due to their potential health hazard. Not to mention, these ingredients are poorly perceived by consumers who opt for a safer natural approach to food preservation. The application of plant extracts as natural antioxidants has become a preferable choice in these recent years to preserve fish products [6]. An example of a natural product which was the main interest of this research was bee bread.

In recent years, bee pollen has been added to various feed and food ingredients such as bakery products, beverages, and meat to improve the nutritional, functional, and sensory values of these newly formulated products [7]. Bee bread is made from pollen, added with bee salivary enzymes and nectar. It is stored and fermented in the beehives [8]. Recently, bee bread from Malaysian stingless bee, Heterotrigona itama, is characterized with high protein, carbohydrate, minerals content, and traces of vitamin C [9]. It is also rich in phenolic compounds, which have been shown to attribute toward its antioxidant and antibacterial properties in vitro [10-12]. For these reasons, it is intriguing to analyze bee bread extract, not only as a potential natural preservative in fish sausage during storage but also to enhance its nutritional values for consumer consumption.

Thus, the objectives of this study were to fortify fish sausages with bee bread extracts at different concentrations. Then, their nutritional composition, total phenolic and flavonoid content, antioxidant and lipid peroxidation activity, antibacterial activity, and microbial analysis were investigated during storage period.

\section{Materials and Methods}

\subsection{Sample Preparation}

2.1.1. Bee Bread Extract. Fresh bee bread sample was collected from Ladang 10, Faculty of Agriculture, Universiti Putra Malaysia from stingless bee Heterotrigona itama colony in 2018. Samples were obtained using sterile spatula and placed inside sterile falcon tubes before storing in a chiller at $4^{\circ} \mathrm{C}$.

Bee bread extract (BBE) was prepared by modifying the method of Urcan et al. [13] using 70\% ethanol as solvent. For every $25 \mathrm{~g}$ of fresh bee bread, $250 \mathrm{~g}$ of $70 \%$ ethanol was added. The mixture was boiled using Soxhlet apparatus for $2 \mathrm{~h}$. The obtained solution was then filtered using a filter paper and the filtrate was evaporated using a rotary evaporator and then evaporated in a water bath at $50^{\circ} \mathrm{C}$ until the solvent was fully evaporated when the constant weight was achieved. BBEs were stored in a Falcon tube in $4^{\circ} \mathrm{C}$ chiller before use.

2.1.2. Fish Sausages. Fish sausages were prepared and modified from a formulation provided by the Department of Fisheries, Malaysia (2014), at concentrations of $0 \%$ (negative control), $0.25 \%$, and $0.5 \%$ of $\mathrm{BBE}$ and with preservative (positive control) as shown in Table 1.

The ingredients were bought from a local store in Seri Kembangan, Selangor, Malaysia. The fish sausages were prepared according to a method by Nor-Khaizura et al. [1]. The fish were cleaned, deboned, and minced before mixing with other ingredients. The mixture was mixed until a soft dough was formed. The dough was rolled into a cylindrical shape with a length $10 \mathrm{~cm}$ each and boiled at $100^{\circ} \mathrm{C}$ until the fish sausage float. It was then cooled down at room temperature before being sealed in a transparent plastic bag and kept stored in a chiller at $4^{\circ} \mathrm{C}$.

2.1.3. Fish Sausage Extract (FSE). Fish sausage extract (FSE) was prepared using the method of Ismail et al. [14] with few modifications. The raw fish sausages were defatted before being extracted. Three grams ( $3 \mathrm{~g}$ ) of finely chopped raw fish sausages was mixed with $30 \mathrm{~mL}$ of $n$-hexane (Merck, Germany) and sonicated in a sonicator (PowerSonic 505, Hwashin Technology Co., Seoul, Korea) for $1 \mathrm{~h}$. The fish sausages were centrifuged for $10 \mathrm{~min}$ and the supernatant was removed. Then, the defatted fish sausages were added with $30 \mathrm{~mL}$ of methanol. The mixture was homogenized (Homogenizer Multi-Gen 7, USA) for $10 \mathrm{~min}$ at $2000 \mathrm{rpm}$ before being sonicated for $2 \mathrm{~h}$ at $30^{\circ} \mathrm{C}$. The sample was centrifuged at $7500 \mathrm{rpm}$ for $10 \mathrm{~min}$ at $25^{\circ} \mathrm{C}$. FSE was transferred into tubes for $1 \mathrm{~mL}$ with a concentration of $1000 \mathrm{mg} / \mathrm{L}$ each and stored at $-80^{\circ} \mathrm{C}$ for antioxidant analysis usage.

2.2. Proximate Analysis. The proximate analysis was performed for fish sausages added with $0 \%, 0.25 \% 0.50 \%$, and $0.75 \%$ of BBE and with synthetic additives. Each sample was first homogenized using quartering technique by cutting them into small pieces and homogenously mixed before performing analysis using method from AOAC [15]. 
The crude protein was determined using the Kjeldahl method and calculated using the conversion factor of 6.25 $(N \times 6.25)$ (AOAC 981.10). The crude fat content was determined using the Soxhlet method (Soxtec ${ }^{\mathrm{TM}} 2050$ Auto Fat Extraction System, FOSS Analytical, Denmark) (AOAC 991.36). The moisture content was determined by using oven drying method (Memmert GmbH + Co. KG, Germany) at $105^{\circ} \mathrm{C}$ until a constant weight was achieved (AOAC 950.46). The ash content was determined using a muffle furnace at temperature $600^{\circ} \mathrm{C}$ for at least 4 hours until there was no presence of black ash (AOAC 923.03). Dietary fibre was determined using chemical digestion in sulphuric acid and sodium hydroxide. The total carbohydrate was obtained by difference as follows:

$$
g \text { carbohydrates }=100 g-(g \text { moisture }+g \text { lipid }+g \text { protein }+g \text { ash }) .
$$

2.3. Determination of Total Phenolic Content (TPC). The TPC was determined by the Folin-Ciocalteu method according to Roy et al. [16] with minor modifications. The FSE samples were prepared in diluted concentration of $500 \mathrm{mg} / \mathrm{L}$. Briefly, $100 \mu \mathrm{L}$ of sample was added with $500 \mu \mathrm{L}$ of diluted Folin-Ciocalteu's reagent and then vortexed. Then, $400 \mu \mathrm{L}$ of sodium carbonate was added and vortexed again. The mixture was incubated for 1 hour at $40^{\circ} \mathrm{C}$ in the dark. Then, $200 \mu \mathrm{L}$ of the mixture was loaded into 96-well plates and the absorbance was measured at $765 \mathrm{~nm}$ using microplate readers (Synergy ${ }^{\mathrm{TM}} \mathrm{H} 1$ microplate reader, BioTek Instruments, Inc., USA). Gallic acid and $1000 \mu \mathrm{L}$ methanol were used as the standard and blank, respectively. The results were expressed as mg gallic acid equivalent (GAE)/g fish sausage.

\subsection{Determination of Total Flavonoid Content (TFC). The} TFC was determined by the aluminium calorimetric method according to Chakraborty et al. [17] with minor modifications. The FSE samples were prepared in diluted concentration of $500 \mathrm{mg} / \mathrm{L}$. The samples $(100 \mu \mathrm{L})$ were mixed with $100 \mu \mathrm{L}$ of $2 \% \mathrm{AlCl}_{3}$ solution. The mixtures were incubated for 15 minutes at room temperature in the dark condition. Then, $200 \mu \mathrm{L}$ of the mixture was loaded into 96-well plates, and the absorbance was measured at $435 \mathrm{~nm}$ using a microplate reader (Synergy ${ }^{\mathrm{TM}} \mathrm{H} 1$ microplate reader, BioTek Instruments, Inc., USA). Rutin and $200 \mu \mathrm{L}$ methanol were used as the standard and blank, respectively. The results of the scavenging activity were expressed as $\mathrm{mg}$ rutin/g fish sausage.

\subsection{Determination of 2,2-Diphenyl-1-picrylhydrazyl (DPPH)} Radical Scavenging Activity. The antioxidant activity was evaluated by DPPH radical scavenging assay according to the method described by Ismail et al. [14] with some modifications. The FSE samples were prepared in diluted concentration of $500 \mathrm{mg} / \mathrm{L}$. The samples $(50 \mu \mathrm{L})$ were mixed with $195 \mu \mathrm{L}$ of diluted DPPH stock solution in 96-well plate. The plate was incubated at room temperature in dark condition for $1 \mathrm{~h}$. The absorbance was measured at $540 \mathrm{~nm}$ using a microplate reader (Synergy ${ }^{\mathrm{TM}} \mathrm{H} 1$ microplate reader, BioTek Instruments, Inc., USA). Gallic acid and $245 \mu \mathrm{L}$ of methanol were used as the standard and blank, respectively. DPPH radical scavenging activity was expressed as mg GAE/ $\mathrm{g}$ fish sausages. The antioxidant activity (\%) of the sample was calculated according to the following equation:

$$
\% \text { scavenging activity }=\frac{A_{\text {control }}-A_{\text {sample }}}{A_{\text {control }}} .
$$

2.6. Thiobarbituric Acid Reactive Substances (TBARS) Assay. The lipid peroxidation of the fish sausages was determined by TBARS assay described by Chan et al. [18] with few modifications. Firstly, $50 \mathrm{mg}$ of fish sausage sample was added with $50 \mu \mathrm{L}$ of distilled water. Then, $50 \mu \mathrm{L}$ of the diluted sample was mixed with $250 \mu \mathrm{L}$ of $0.25 \mathrm{~N} \mathrm{HCl}, 250 \mu \mathrm{L}$ of trichloroacetic acid $(15 \%, \mathrm{w} / \mathrm{v})$, and $250 \mu \mathrm{L}$ of thiobarbituric acid solution $(0.375 \%, \mathrm{w} / \mathrm{v})$. The mixtures were vortexed before incubation in a water bath at $100^{\circ} \mathrm{C}$ for $10 \mathrm{~min}$. The mixture was cooled down and centrifuged at $3000 \mathrm{rpm}$ for $15 \mathrm{~min}$. Then, $100 \mu \mathrm{L}$ of the supernatant was loaded in a 96well microplate. The absorbance was measured at $540 \mathrm{~nm}$ (Synergy $^{\mathrm{TM}} \mathrm{H} 1$ microplate reader, BioTek Instruments, Inc., USA). 1,1,3,3-tetramethoxypropane (TMP) and $800 \mu \mathrm{L}$ of the distilled water were used as the standard and blank, respectively. The result was expressed in $\mathrm{mg} \mathrm{MDA} / \mathrm{kg}$.

2.7. Antibacterial Activity of Bee Bread Extract (BBE). The antibacterial activity of the BBE against foodborne pathogens was determined using disc diffusion method according to the method of Akhir et al. [10]. The extracts were tested against Staphylococcus aureus, Escherichia coli, Bacillus cereus, and Salmonella typhimurium, which were obtained from the Institute of Bioscience, UPM. The overnight bacterial suspension was grown at $37^{\circ} \mathrm{C}$, and the concentration was adjusted to $0.5 \mathrm{McF}$ arland. Then, $100 \mu \mathrm{L}$ of the bacterial solution was spread on Mueller-Hinton Agar (MHA) (Oxoid, UK). Meanwhile, $6 \mathrm{~mm}$ sterile disc was impregnated with $20 \mu \mathrm{L}$ of $\mathrm{BBE}$ at $1 \mathrm{~g} / \mathrm{mL}$ and left to dry before placing it onto the agar. Tetracycline $(30 \mathrm{mg} / \mathrm{ml})$ was used as a positive control. The agar plate was incubated for $24 \mathrm{~h}$ at $37^{\circ} \mathrm{C}$. The zone of inhibition was measured in $\mathrm{mm}$.

2.8. Microbial Quality. The microbial analysis of fish sausage during shelf life was analyzed according to Mohammad et al. [19] with slight modifications. The fish sausages were stored in a freezer at $0^{\circ} \mathrm{C}$ and the microbial count was calculated after $0,2,4$, and $6 \mathrm{~d}$ of storage. After the designated time, $10 \mathrm{~g}$ of the fish sausages was added with $90 \mathrm{~mL}$ of $0.1 \%$ buffered peptone water and digested in a Stomacher bag using a Stomacher for $2 \mathrm{~min}$. Four 10-serial dilutions were prepared using peptone water and $1 \mathrm{~mL}$ of diluent was spread onto 
TABLe 2: Proximate composition of fish sausages fortified with different percentage of bee bread extract (BBE) and positive control.

\begin{tabular}{lcccccc}
\hline & \multicolumn{5}{c}{ Proximate composition (\%) } & \\
Fish sausage & Crude protein & Crude fat & Moisture & Ash & Fibre & Carbohydrate \\
\hline $0.0 \%$ BBE & $12.74 \pm 1.03$ & $1.60 \pm 1.25$ & $47.79 \pm 0.71^{\mathrm{a}}$ & $8.11 \pm 0.19$ & $0.081 \pm 0.001^{\mathrm{a}}$ & $28.12 \pm 1.40^{\mathrm{b}}$ \\
$0.25 \% \mathrm{BBE}$ & $12.24 \pm 0.63$ & $1.20 \pm 0.92$ & $47.33 \pm 0.58^{\mathrm{a}}$ & $8.17 \pm 0.09$ & $0.078 \pm 0.001^{\mathrm{b}}$ & $29.50 \pm 0.89^{\mathrm{b}}$ \\
$0.5 \% \mathrm{BBE}$ & $14.47 \pm 2.58$ & $1.33 \pm 0.12$ & $48.33 \pm 0.57^{\mathrm{a}}$ & $8.22 \pm 0.01$ & $0.082 \pm 0.001^{\mathrm{a}}$ & $26.01 \pm 2.79^{\mathrm{b}}$ \\
$0.75 \% \mathrm{BBE}$ & $13.00 \pm 1.97$ & $0.47 \pm 1.97$ & $40.33 \pm 0.58^{\mathrm{b}}$ & $7.98 \pm 0.11$ & $0.082 \pm 0.001^{\mathrm{a}}$ & $36.59 \pm 1.26^{\mathrm{a}}$ \\
Synthetic* & $11.36 \pm 0.89$ & $1.40 \pm 0.40$ & $41.30 \pm 0.58^{\mathrm{b}}$ & $8.18 \pm 0.03$ & $0.077 \pm 0.001^{\mathrm{b}}$ & $36.18 \pm 1.77^{\mathrm{a}}$ \\
\hline
\end{tabular}

Values of means \pm standard deviation (SD) of triplicate independent experiments. Different letters in the same column mean significant difference $(p<0.05)$. * Potassium sorbate.

plate count agar (Oxoid, UK) before being incubated aerobically at $37^{\circ} \mathrm{C}$ for $24 \mathrm{~h}$. The viable colonies were enumerated and expressed as $\log _{10} \mathrm{CFU} / \mathrm{mL}$.

2.9. Statistical Analysis. All of the data were obtained in triplicate $(n=3)$ and the results were expressed as mean$\mathrm{s} \pm$ standard deviations. Data were analyzed using Minitab version 17 using one-way ANOVA tests. If ANOVA test indicated a significant result $(p<0.05)$, then the significant means were separated using Tukey's test.

\section{Results and Discussion}

3.1. Proximate Composition. The proximate composition of the fish sausages fortified with BBE and synthetic additive is shown in Table 2. Higher BBE concentration in fish sausages significantly $(p<0.05)$ reduced the moisture level and increased the carbohydrate content.

Moisture above $40 \%$ is not favorable as it could promote the microbial growth in fish sausages [20]. By increasing the incorporation of $\mathrm{BBE}$ from 0 to $0.75 \%$, the moisture level decreased from 47.79 to $40.33 \%$. Increment in pollen concentration also decreased the moisture content when added to meatballs [21] and gluten-free bread [22]. One of the possible factors of decreasing moisture content is due to the substitution of sago starch to make fish sausage with BBE. Sago starch contains high amylopectin, which has high water absorbing capacity [23]. Hence, lowering sago starch content reduces fish sausages' moisture level.

Carbohydrate content significantly increased $(p<0.05)$ from 28.93 to $37.41 \%$ in $0.75 \%$ BBE fish sausage compared to the negative control. $H$. itama bee bread and its extract contain about 55 to $58 \%$ carbohydrate $[9,24]$. This could compensate for the loss of carbohydrate content contributed by sago starch.

However, there was no significant difference $(p>0.05)$ for protein, fat, and ash content between fish sausages at different BBE concentrations. BBE did not affect these nutritional parameters. Protein was the second-largest macronutrient found contributed by the Indian mackerel fish, which is the primary protein source for all the samples. The fish mass used in the formulations was constant; thus, it had no effect on the samples' protein level. Similarly, protein content in the fish sausage was also not affected when incorporated with seaweed [19]. Although the $H$. itama bee bread contains an average of $22.26 \%$ protein
(Mohammad et al., 2020), it showed an insignificant effect towards fish sausage protein when added at low concentration. The samples' protein level could be increased when a higher bee bread concentration, minimum at $1 \%$, is added to the food system [21, 22].

The fat and ash content were also constant in all sample concentrations because $H$. itama bee bread contains a minute amount of these nutrients [9]. Even at high concentrations, bee bread had shown to not affect these nutrients' values [21].

\subsection{Total Phenolic Content and Total Flavonoid Content.} Figure 1 shows the total phenolic content (TPC) for fish sausage samples fortified with BBE and synthetic additive BHT. The TPC in fish sausages significantly increased $(p<0.05)$ when the concentration of BBE in the samples increased. On day 1, the TPC varied among samples from 14.87 to $23.46 \mathrm{mg}$ GAE/g sample. Fish sausage fortified with $0.75 \%$ BBE had the highest TPC content (23.46 mg GAE/g sample) compared to other concentrations and sample with BHT.

This result was higher than other reported studies of food fortified with bee pollen. For example, phenolic content in sheep milk yoghurt enriched with bee pollen was $8.78 \mathrm{mg}$ GAE/g [25]. In another study, Krystyjan et al. [26] reported $4.84 \mathrm{mg} \mathrm{GAE} / \mathrm{g}$ in $10 \%$ bee pollen biscuits while Conte et al. [22] only reported a maximum of $4.42 \mathrm{mg} \mathrm{GAE} / \mathrm{g}$ in $5 \%$ bee pollen bread. According to Othman et al. [27], Malaysia H. itama bee bread is rich in phenolic compounds as it was reported to contain up to $22.4 \mathrm{mg} \mathrm{GAE} / \mathrm{g}$.

However, the results showed a decreasing trend $(p<0.05)$ after 14 and 28 days (Figure 1$)$. On day 14, fish sausages with 0.25 to $0.75 \%$ BBE had significantly higher phenolic content $(p<0.05)$ than control and BHT. But after 28 days, the phenolic content in all samples was not statistically different $(p>0.05)$ from each other. Loss of phenolic compounds can happen at low-temperature storage between 4 and $8^{\circ} \mathrm{C}$ [28] as the oxidation process gradually degrades these compounds.

Flavonoid is the most prevalent phenolic compounds group. Figure 2 displays the total flavonoid content (TFC) for fish sausage samples fortified with BBE and with BHT. The TFC in fish sausages significantly increased $(p<0.05)$ when the concentration of BBE in the samples increased. On day 1 , the TFC varied from 2.90 to $8.05 \mathrm{mg}$ rutin/g sample. The highest TFC content was recorded for fish sausage fortified with $0.75 \%$ BBE (8.05 mg rutin/g sample). 


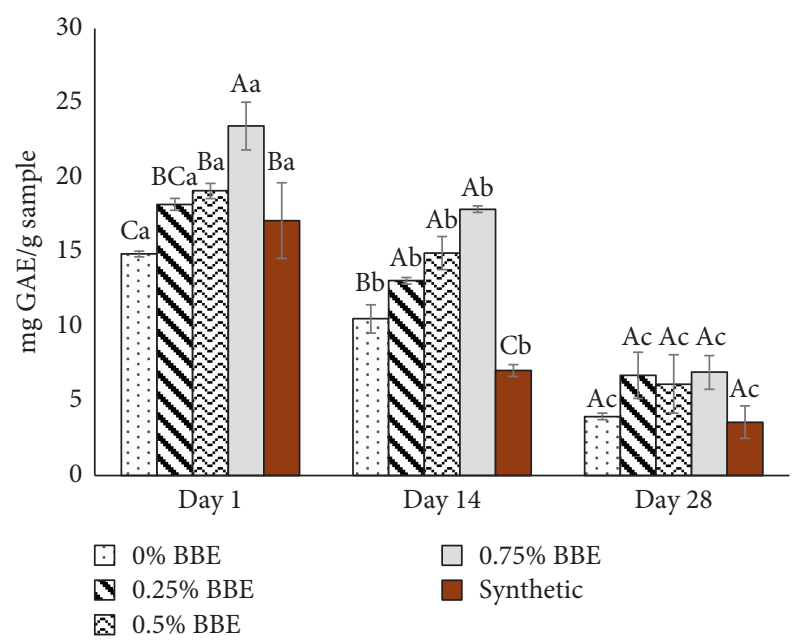

Figure 1: The total phenolic content (mg GAE/mg sample) of fish sausages samples fortified with $0 \%, 0.25 \%$, and $0.5 \% \mathrm{BBE}$ and synthetic additives BHT. Values of means \pm standard deviation (SD) of triplicate independent experiments. Different capital letters indicate significant differences $(p<0.05)$ within the samples in the same day. Different small letters indicate significant differences $(p<0.05)$ of the same sample across the storage days 1,14 , and 28 at $4^{\circ} \mathrm{C}$.

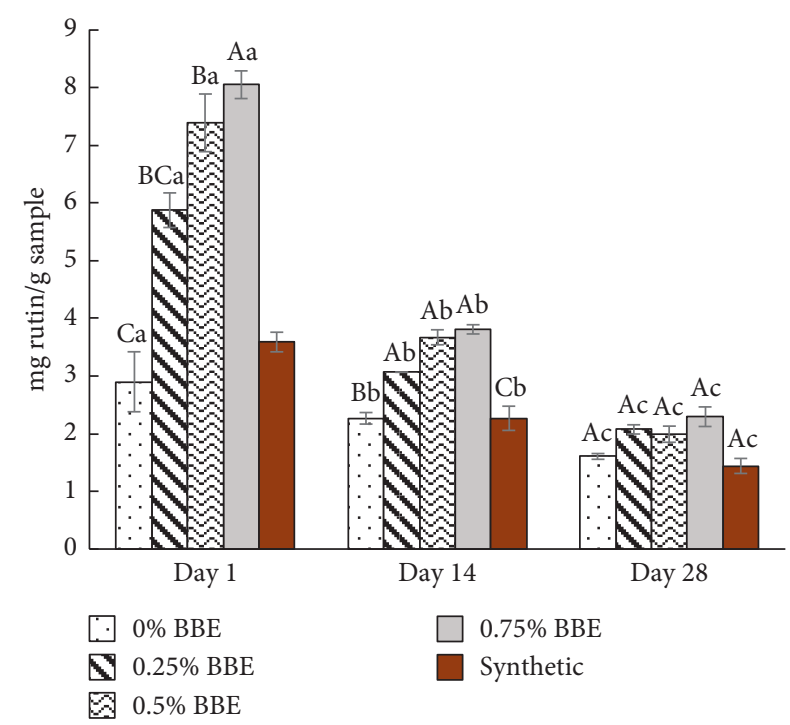

Figure 2: The total flavonoid content (mg rutin/g sample) of fish sausage samples fortified with $0 \%, 0.25 \%$, and $0.5 \% \mathrm{BBE}$ and synthetic additive BHT. Values of means \pm standard deviation (SD) of triplicate independent experiments. Different capital letters indicate significant differences $(p<0.05)$ within the samples in same day. Different small letters indicate significant differences $(p<0.05)$ of the same sample across the storage days 1,14 , and 28 at $4^{\circ} \mathrm{C}$.

Studies on flavonoid content of food incorporated with bee bread or bee pollen are scarce even though the commonly found phenolic compounds in bee bread were flavonoids such as kaempferol, quercetin, and luteolin [29]. According to Othman et al. [30], TFC in H. itama BBE was in the range of 16.71 to $26.57 \mathrm{mg} \mathrm{QE} / \mathrm{g}$ extract. Nevertheless, in this study, the TFC range for BBE fish sausages was

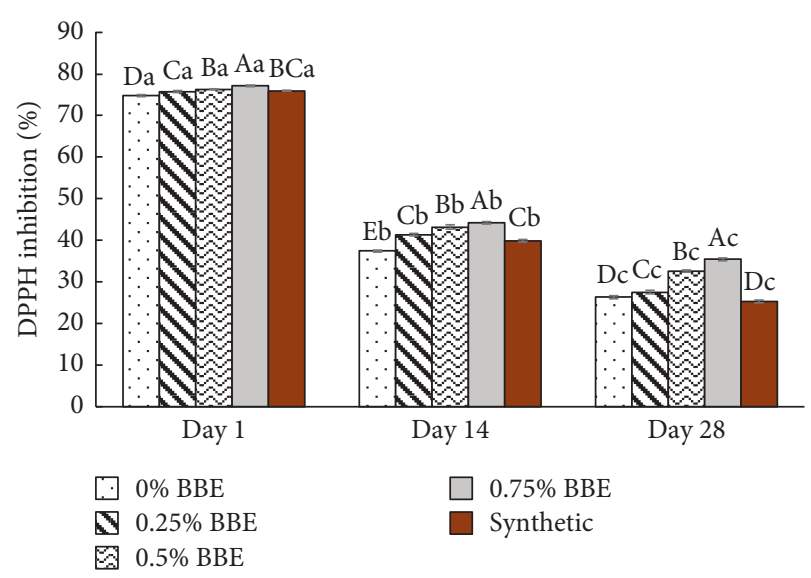

FIGURE 3: The DPPH radical scavenging activity (\%) of fish sausages samples fortified with $0 \%, 0.25 \%$, and $0.5 \%$ BBE and synthetic additives. Values of means \pm standard deviation (SD) of triplicate independent experiments. Different capital letters indicate significant differences $(p<0.05)$ within the samples in the same day. Different small letters indicate significant differences $(p<0.05)$ of the same sample across the storage days 1,14 , and 28 at $4^{\circ} \mathrm{C}$.

incredibly low (1.99 to $8.05 \mathrm{mg}$ rutin/sample). Higher temperature imposed on fish sausages during the boiling stage could degrade some of the flavonoid compounds.

Variation of phenolic and flavonoid content could also be attributed to different extraction methods. In addition, bee bread phenolic compounds are also influenced by the botanical origin and geographical origin of the pollen.

3.3. DPPH Activity and TBARS Activity. DPPH activity measures the extract ability to scavenge the free radical molecules (DPPH). Figure 3 shows the DPPH radical scavenging activity for fish sausage samples fortified with $\mathrm{BBE}$ and synthetic additive BHT. On day 1, the fish sausage fortified with $0.75 \% \mathrm{BBE}$ recorded the highest $\mathrm{DPPH}$ activity $(77.15 \%)$, higher than fish sausages with BHT $(p<0.05)$. Meanwhile, fish sausage without BBE recorded the lowest (74.80\%).

This study reported higher DPPH inhibition activity than gluten-free bread fortified with bee pollen [22]. The antioxidant activity of fish sausage bee bread was partly due to the presence of phenolic compounds such as isorhamnetin, kaempferol, and apigenin and also vitamin $\mathrm{C}$ found in $H$. itama bee bread $[9,27]$. Incorporation of bee bread or bee pollen has also shown to increase the DPPH radical scavenging activity in biscuit [31], gluten-free bread [22], and yoghurt milk [25]. Similar to this study, the antioxidant activities of these bee pollen products were shown to be positively correlated to the bee pollen concentrations added to the product [22].

However, storage until 28 days significantly reduced $(p<0.05)$ the DPPH activity by the samples. Yet, $0.75 \% \mathrm{BBE}$ fish sausage had the highest DPPH inhibition values $(p<0.05)$ compared to fish sausages with other concentrations and with BHT. When the storage period increased, the available phenolic compounds to oxidize free radicals in 
TABLE 3: The thiobarbituric acid reactive substance (TBARS) inhibitory activity (mg MDA/kg) of fish sausage samples fortified with $0 \%$, $0.25 \%$, and $0.5 \% \mathrm{BBE}$ and synthetic additives BHT after storage for 1,14 , and 28 days at $4^{\circ} \mathrm{C}$.

\begin{tabular}{lccccc}
\hline & & \multicolumn{3}{c}{ TBARS values (mg MDA/kg) } & \\
& $0 \%$ BBE & $0.25 \%$ BBE & $0.5 \%$ BBE & $0.75 \%$ BBE & Synthetic \\
\hline Day 1 & $3.30 \pm 0.22^{\mathrm{Aa}}$ & $3.10 \pm 0.06^{\mathrm{Aa}}$ & $1.16 \pm 0.01^{\mathrm{Ca}}$ & $0.59 \pm 0.11^{\mathrm{Da}}$ & $2.19 \pm 0.23^{\mathrm{Ba}}$ \\
Day 14 & $5.50 \pm 0.18^{\mathrm{Ab}}$ & $5.41 \pm 0.90^{\mathrm{Ab}}$ & $3.89 \pm 0.07^{\mathrm{Bb}}$ & $3.61 \pm 0.25^{\mathrm{Bb}}$ & $3.07 \pm 0.51^{\mathrm{Ba}}$ \\
Day 28 & $24.14 \pm 0.96^{\mathrm{Ac}}$ & $14.40 \pm 0.69^{\mathrm{Bc}}$ & $14.29 \pm 14.29^{\mathrm{Bc}}$ & $12.84 \pm 0.70^{\mathrm{BCc}}$ & $11.92 \pm 0.59^{\mathrm{Cb}}$ \\
\hline
\end{tabular}

Values of means \pm standard deviation (SD) of triplicate independent experiments. Different capital letters in the same row indicate significant differences $(p<0.05)$. Different small letters in the same column indicate significant differences $(p<0.05)$.

fish sausages were reduced (Figure 1). Consequently, the antioxidant activities became lowered.

Malonyldialdehyde (MDA) is one of the end products of lipid oxidation and can be considered as a biomarker for oxidative stress [32]. The determination of lipid peroxidation in the fish sausages was conducted using TBARS assay that measured the amount of MDA-TBA complex in the sample. The effectiveness of the natural antioxidants, which was BBE, in reducing the lipid oxidation in the fish sausage was demonstrated after 14 and 28 days of refrigeration at $4^{\circ} \mathrm{C}$.

Table 3 illustrates the TBARS activity for the fish sausage samples. After 1 day of storage, fish sausages fortified with $0.75 \%$ had the lowest TBARS activity $(0.59 \mathrm{mg} \mathrm{MDA} / \mathrm{kg}$ ) than other samples, including samples with BHT. Meanwhile, sample without BBE showed the highest TBARS value and significantly no difference $(p>0.05)$ compared to the sample with $0.25 \%$ BBE.

After 28 days of refrigeration, the TBARS activities for fish sausages with $0.75 \% \mathrm{BBE}$ were similar $(p>0.05)$ to fish sausage with BHT. Using a higher concentration of BBE was able to protect and delay lipid oxidation, which was indicated by low TBARS values. This result is in agreement with Almeida et al. [33], which demonstrated that $0.2 \mathrm{~g} / \mathrm{kg}$ lyophilized bee pollen in pork sausages lowered the TBARS value compared to control after 30 days refrigeration. Turhan et al. [34] also reported the lowest TBARS values in 4.5 and $6.0 \%$ meatballs bee pollen after 30 days of storage.

However, this research observed an increasing trend $(p<0.05)$ in the TBARS value after 28 days of storage, indicating an increase in lipid oxidation in fish sausages. This result was similar to other meat products added with bee pollen $[33,34]$. At low-temperature storage, lipid inhibition still occurs but at a slower rate [33]. Some of the phenolic compounds could be degraded and could not compensate for the increase of lipid oxidation throughout storage. This was observed by the gradual loss of phenolic compounds reported in the previous section (Figures 1 and 2). TBARS could also be increased because of the partial dehydration and oxidation of unsaturated fatty acids [35], especially when Malaysian Indian mackerel fish contain high unsaturated fatty acids [4].

TBARS values also provide insight towards meat odor and consumer acceptance. Consumers more likely to detect rancid odors at MDA concentration above $0.5 \mathrm{mg} \mathrm{MDA} / \mathrm{kg}$ [36]. Besides, meat products are suggested to be favourable with less than $3 \mathrm{mg} \mathrm{MDA} / \mathrm{kg}$ sample [37]. In this study, after 14 days of storage, all fish sausage samples recorded TBARS values above $3 \mathrm{mg} \mathrm{MDA} / \mathrm{kg}$. Fish sausages have an approximate 2 weeks of shelf life in the chilled refrigerator.

Based on the result from DPPH and TBARS activity, this shows BBE ability as a natural antioxidant to inhibit lipid oxidation in fish sausage at a high concentration similar to BHT. The lipid oxidation is dependent on the BBE concentration and storage period.

3.4. Antibacterial Activity of Bee Bread Extract (BBE). Table 4 displays the antibacterial activity of BBE against foodborne pathogens. BBE showed the highest antibacterial activity against $S$. aureus followed by $B$. cereus, S. typhimurium, and E. coli. BBE was more effective $(p<0.05)$ against the tested pathogens compared to tetracycline (positive control).

This result is in agreement with those of Akhir et al. [10], which showed the ability of bee bread ethanolic extract to inhibit S. aureus, B. subtilis, E. coli, and Salmonella sp. growth. However, there was variation in the degree of inhibition as it was influenced by bacteria type. Gram-negative bacteria such as E. coli and S. typhimurium are more resistant to the antimicrobial agent because they have thicker peptidoglycan cell walls, which acts as a barrier to hydrophobic compounds penetration [38]. According to Sulbarán-Mora et al. [39], bee bread antibacterial activity was correlated to its phenolic content.

3.5. Microbial Quality. Table 5 shows the plate count of fish sausages fortified with BBE and synthetic additive during shelf life at days $0,2,4$, and 6 . The total plate count $\left(\log _{10} \mathrm{CFU} / \mathrm{g}\right)$ increased across the sample from day 0 until day 6. After 6 days, fish sausages without BBE had the highest microbial count with $5.21 \pm 0.86 \log _{10} \mathrm{CFU} / \mathrm{g}$ while fish sausages with synthetic additive recorded the lowest with $3.50 \pm 1.29 \log _{10} \mathrm{CFU} / \mathrm{g}$. However, these differences were not statistically different $(p>0.05)$.

Fish sausages were boiled beforehand, which reduced the microbial count significantly $[1,40]$. Adequate boiling was able to fully eliminate the growth of $S$. aureus and Vibrio sp. in fish sausages [40]. Thus, no presence of microbial growth was observed at the beginning of day 0 . Still, boiled fish sausages can be contaminated by microorganisms in the postboiling process (cooling stage) as observed by Nor-Khaizura et al. [1]. They reported a microbial growth increase to $6.44 \log _{10} \mathrm{CFU} / \mathrm{g}$ during the cooling stage. Some of the assumptions for these different observations were probably due to the differences in boiling and 
TABLE 4: The antibacterial activity of bee bread extract (BBE) against foodborne pathogens.

\begin{tabular}{lcccc}
\hline & \multicolumn{2}{c}{ Zone of inhibition $(\mathrm{mm})$} & & \\
Fish sausage & Escherichia coli & Salmonella typhimurium & Staphylococcus aureus & Bacillus cereus \\
\hline BBE $(1 \mathrm{~g} / \mathrm{ml})$ & $23.00 \pm 1.41^{\mathrm{a}}$ & $31.00 \pm 1.41^{\mathrm{a}}$ & $43.50 \pm 2.12^{\mathrm{a}}$ & $31.00 \pm 1.41^{\mathrm{a}}$ \\
Tetracycline $(30 \mathrm{mg} / \mathrm{ml})$ & $17.50 \pm 0.70^{\mathrm{b}}$ & $20.5 \pm 0.70^{\mathrm{b}}$ & $3.95 \pm 0.07^{\mathrm{b}}$ & $18.00 \pm 0.70^{\mathrm{b}}$ \\
\hline
\end{tabular}

Tetracycline is the positive control. Values of means \pm standard deviation (SD) of triplicate independent experiments. Different letters in the same column mean significant difference $(p<0.05)$.

TABLE 5: Total plate count $\left(\log _{10} \mathrm{CFU} / \mathrm{g}\right)$ of fish sausages fortified with different concentrations of bee bread extract (BBE) and synthetic additive potassium sorbate after $0,2,4$, and 6 days of shelf life at $0^{\circ} \mathrm{C}$.

\begin{tabular}{|c|c|c|c|c|}
\hline \multirow[b]{2}{*}{ Fish sausage } & \multicolumn{2}{|c|}{ Total plate count $\left(\log _{10} \mathrm{CFU} / \mathrm{g}\right)$} & \multirow[b]{2}{*}{ Day 4} & \multirow[b]{2}{*}{ Day 6} \\
\hline & Day 0 & Day 2 & & \\
\hline $0 \% \mathrm{BBE}$ & $0.00^{\mathrm{a}}$ & $3.55 \pm 2.63^{\mathrm{bA}}$ & $4.86 \pm 0.84^{\mathrm{b}}$ & $5.21 \pm 0.86^{\mathrm{b}}$ \\
\hline $0.25 \% \mathrm{BBE}$ & $0.00^{\mathrm{a}}$ & $0.00^{\mathrm{aB}}$ & $3.90 \pm 0.84^{\mathrm{b}}$ & $3.84 \pm 0.87^{\mathrm{b}}$ \\
\hline $0.50 \% \mathrm{BBE}$ & $0.00^{\mathrm{a}}$ & $3.75 \pm 0.95^{\mathrm{bA}}$ & $4.15 \pm 0.59^{\mathrm{b}}$ & $3.32 \pm 0.47^{\mathrm{b}}$ \\
\hline $0.75 \% \mathrm{BBE}$ & $0.00^{\mathrm{a}}$ & $3.61 \pm 1.87^{\mathrm{bA}}$ & $3.50 \pm 1.29^{\mathrm{b}}$ & $4.86 \pm 1.64^{\mathrm{b}}$ \\
\hline Synthetic $^{1}$ & $0.00^{\mathrm{a}}$ & $3.32 \pm 0.47^{\mathrm{bA}}$ & $3.50 \pm 1.29^{\mathrm{b}}$ & $3.50 \pm 1.29^{\mathrm{b}}$ \\
\hline
\end{tabular}

${ }^{1}$ Synthetic potassium sorbate. Values of means \pm standard deviation (SD) of triplicate independent experiments. Different capital letters in same column mean significant difference $(p<0.05)$. Different small letters in same row mean significant difference $(p<0.05)$.

sterile handling techniques in. these studies. However, cross-contamination is more likely to happen from food handlers and food contact surfaces on the scene [40].

The fish sausages were later stored in the freezer at $0^{\circ} \mathrm{C}$, whereas the microbial counts were shown to gradually increase until day 6 . Still, all of the samples showed a microbial count lower than $6 \log _{10} \mathrm{CFU} / \mathrm{g}$, which is the standard limit set for fish products ready for consumption according to Malaysia Food and Agricultural Organization (2017). Increment of microbial loads also suggests the growth of psychrophile bacteria that thrive in low temperature in fishbased products [41]. On day 6 , fish sausage with BBE showed lower microbial count than control. This is in conjunction with the finding from the previous section which demonstrated the efficiency of the BBE against the tested microbes in vitro.

Thus, the result indicated that BBE was as efficient as a synthetic preservative in reducing the microbial load in fish sausages during 6 days of frozen storage compared to without preservative.

\section{Conclusions}

The effect of BBE at different concentrations on the proximate, phenolic compounds, and antioxidant and antibacterial activity in fish sausages has been studied. It demonstrated the BBE has a potential as a natural antioxidant and antibacterial agent in fish sausages. However, its efficacy relatively depends on the BBE concentration and storage period. In the future, more study should be conducted to determine BBE effects on the fish sausage physical properties and the final product acceptance among consumers.

\section{Data Availability}

The data used to support the findings of this study are included within the article.

\section{Conflicts of Interest}

The authors declare that they have no conflicts of interest regarding the publication of this paper.

\section{Acknowledgments}

The authors acknowledge the contribution of the laboratory staff and assistants of the Faculty of Food Science and Technology, UPM, for assisting in the lab works and in providing all the equipment needed for making the food products. This research was funded by Universiti Putra Malaysia under the Putra Grant Scheme GP/2017/9568900.

\section{References}

[1] M. A. R. Nor-Khaizura, H. Zaion, B. Jamilah, and R. A. Gulam Rusul, "Microbiological quality of keropok lekor during processing," International Food Research Journal, vol. 16, pp. 215-223, 2009.

[2] M. Omar, N. Mohd Adzahan, H. Mohd Ghazali, R. Karim, N. M. Abdul Halim, and S. Abkarim, "Sustaining traditional food: consumers' perceptions on physical characteristics of keropok lekor or fish snack," International Food Research Journal, vol. 18, no. 1, pp. 117-124, 2011.

[3] M. Embong, S. Ishak, M. A. A. Rahim, and N. Shafie, "The effect of various treatments on the dehydration of fish sausage," in Proceedings of the Seminar on Advances in Food Research III, Malaysia, November 1990.

[4] N. A. Muhamad and J. Mohamad, "Fatty acids composition of selected Malaysian fishes," Sains Malaysiana, vol. 41, no. 1, pp. 81-94, 2012.

[5] S. Maqsood, S. Benjakul, and F. Shahidi, "Emerging role of phenolic compounds as natural food additives in fish and fish products," Critical Reviews in Food Science and Nutrition, vol. 53, no. 2, pp. 162-179, 2013.

[6] I. Medina, J. M. Gallardo, and S. P. Aubourg, "Quality preservation in chilled and frozen fish products by employment of slurry ice and natural antioxidants," International 
Journal of Food Science \& Technology, vol. 44, no. 8, pp. 1467-1479, 2009.

[7] A. Kostić, D. D. Milinčić, M. B. Barać, M. A. Shariati, Ž. L. Tešić, and M. B. Pešić, "The application of pollen as a functional food and feed ingredient-the present and perspectives," Biomolecules, vol. 10, no. 1, pp. 1-36, 2020.

[8] M. Kieliszek, K. Piwowarek, A. M. Kot, S. Błażejak, A. Chlebowska-Śmigiel, and I. Wolska, "Pollen and bee bread as new health-oriented products: a review," Trends in Food Science \& Technology, vol. 71, pp. 170-180, 2018.

[9] S. M. Mohammad, N. K. Mahmud-Ab-Rashid, and N. Zawawi, "Botanical origin and nutritional values of bee bread of stingless bee (Heterotrigona itama) from Malaysia," Journal of Food Quality, vol. 2020, Article ID 2845757, 17 pages, 2020.

[10] R. A. M. Akhir, M. F. A. Bakar, and S. B. Sanusi, "Antioxidant and antimicrobial activity of stingless bee bread and propolis extracts," AIP Conference Proceedings, vol. 42, no. 1, pp. 72-79, 2018.

[11] N. H. Fadzilah, M. F. Jaapar, R. Jajuli, W. Adnan, and W. Omar, "Total phenolic content, total flavonoid and antioxidant activity of ethanolic bee pollen extracts from three species of Malaysian stingless bee," Journal of Apicultural Research, vol. 8839, pp. 1-6, 2017.

[12] K. S. Mohd and N. B. M. Zin, "Chemical and biological investigation of apiculture products from stingless bees Heterotrigona itama," Journal of Agrobiotechnology, vol. 11, no. 1, pp. 7-19, 2020.

[13] A. C. Urcan, A. D. Criste, D. S. Dezmirean, R. Mărgăoan, A. Caeiro, and M. G. Campos, "Similarity of data from bee bread with the same taxa collected in India and Romania," Molecules, vol. 23, no. 10, pp. 1-19, 2018.

[14] H. I. Ismail, K. W. Chan, A. A. Mariod, and M. Ismail, "Phenolic content and antioxidant activity of cantaloupe (cucumis melo) methanolic extracts," Food Chemistry, vol. 119, no. 2, pp. 643-647, 2010.

[15] Association of official Analytical Chemists, Official Methods of Analysis of AOAC International, K. Helrich, Ed., , Association of Official Analytical Chemists, Washington, DC, USA, 17th edition, 2000.

[16] S. A. Roy, T. K. Pal, and S. Bhattacharyya, "Effect of thermal processing on in vitro antioxidant potential of Capsicum ( Capsicum annuum ) of different ripening stages," Journal of Pharmacy, vol. 8, no. 12, pp. 1751-1756, 2014.

[17] K. Chakraborty, S. Bhattacharjee, T. K. Pal, and S. Bhattacharyya, "Evaluation of in vitro antioxidant potential of Tea (Camelia sinensis) leaves obtained from different heights of Darjeeling Hill, West Bengal," Journal of Applied Pharmaceutical Science, vol. 5, no. 1, pp. 063-068, 2015.

[18] K. W. Chan, N. M. H. Khong, S. Iqbal, S. E. Ch'ng, U. Younas, and A. S. Babji, "Cinnamon bark deodorised aqueous extract as potential natural antioxidant in meat emulsion system: a comparative study with synthetic and natural food antioxidants," Journal of Food Science and Technology, vol. 51, no. 11, pp. 3269-3276, 2014.

[19] S. M. Mohammad, S. F. M. Razali, N. H. N. Mohamad Rozaiman, A. N. Laizani, and N. Zawawi, "Application of seaweed (Kappaphycus alvarezii) in Malaysian food products," International Food Research Journal, vol. 26, no. 2, pp. 1677-1687, 2019.

[20] J. Bakar, "Keropok lekor--boiling and steaming methods of processing," Pertanika, vol. 6, no. 3, pp. 56-60, 1983.

[21] S. Turhan, F. Yazici, F. T. Saricaoglu, M. Mortas, and H. Genccelep, "Evaluation of the nutritional and storage quality of meatballs formulated with bee pollen," Korean Journal for Food Science of Animal Resources, vol. 34, no. 4, pp. 423-433, 2014.

[22] P. Conte, A. Del Caro, P. P. Urgeghe et al., "Nutritional and aroma improvement of gluten-free bread: is bee pollen effective?" LWT-Food Science and Technology, vol. 118, pp. 1-7, 2020.

[23] S. Kormin, F. Kormin, and M. D. H. Beg, "Study on the biodegradability and water adsorption of ldpe/sago starch blend," Journal of Physics: Conference Series, vol. 1150, no. 1, 2019.

[24] W. I. W. Ismail, N. N. Hussin, S. N. F. Mazlan, N. H. Hussin, and M. N. F. M. Radzi, "Physicochemical analysis, antioxidant and anti proliferation activities of honey, propolis and beebread harvested from stingless bee," IOP Conference Series: Materials Science and Engineering, vol. 440, no. 1, pp. 1-7, 2018.

[25] I. K. Karabagias, V. K. Karabagias, I. Gatzias, and K. A. Riganakos, "Bio-functional properties of bee pollen: the case of "bee pollen yoghurt," Coatings, vol. 8, no. 12, 2018.

[26] M. Krystyjan, D. Gumul, R. Ziobro, and A. Korus, "The fortification of biscuits with bee pollen and its effect on physicochemical and antioxidant properties in biscuits," LWT-Food Science and Technology, vol. 63, no. 1, pp. 640-646, 2015.

[27] Z. A. Othman, W. Syaheedah, W. Ghazali et al., "Phenolic compounds and the anti-atherogenic effect of bee bread in high-fat diet-induced obese rats," Antioxidants, vol. 9, no. 1, pp. 1-12, 2020.

[28] A. Rzepecka-Stojko, M. Stec, E. Kurzeja, E. Gawrońska, and K. Pawłowska-Góral, "The effect of storage of bee pollen extracts on polyphenol content," Polish Journal of Environmental Studies, vol. 21, no. 4, pp. 1007-1011, 2012.

[29] P. Vit, G. R. D. Albore, O. M. Barth, M. Peña-vera, and E. Pérez-pérez, "Characterization of pot-pollen from southern Venezuela," in Pot-Pollen in Stingless Bee Melittology, P. Vit, S. R. M. Pedro, and D. W. Roubik, Eds., pp. 361-375, Springer International Publishing, New York, NY, USA, 2018.

[30] Z. Othman, W. S. Wan Ghazali, L. Nordin, N. Omar, and M. Mohamed, "Nutritional, phytochemical and antioxidant analysis of bee bread from different regions of Malaysia," Indian Journal of Pharmaceutical Sciences, vol. 81, pp. 955960, 2019.

[31] M. Solgajová, J. Nôžková, and M. Kadáková, "Quality of durable cookies enriched with rape bee pollen," Journal of Central European Agriculture, vol. 15, no. 1, pp. 24-38, 2014.

[32] M. A. Ghani, C. Barril, D. R. Bedgood, and P. D. Prenzler, "Measurement of antioxidant activity with the thiobarbituric acid reactive substances assay," Food Chemistry, vol. 230, pp. 195-207, 2017.

[33] J. d. F. Almeida, A. S. d. Reis, L. F. S. Heldt et al., "Lyophilized bee pollen extract: a natural antioxidant source to prevent lipid oxidation in refrigerated sausages," LWT - Food Science and Technology, vol. 76, pp. 299-305, 2017.

[34] S. Turhan, F. T. Saricaoglu, M. Mortas, F. Yazici, and H. Genccelep, "Evaluation of color, lipid oxidation and microbial quality in meatballs formulated with bee pollen during frozen storage," Journal of Food Processing and Preservation, vol. 41, no. 3, 2017.

[35] O. Kilincceker, İ. S. Dogan, and E. Kucukoner, "Effect of edible coatings on the quality of frozen fish fillets," LWT-Food Science and Technology, vol. 42, no. 4, pp. 868-873, 2009.

[36] P. R. Sheard, M. Enser, J. D. Wood, G. R. Nute, B. P. Gill, and R. I. Richardson, "Shelf life and quality of pork and pork 
products with raised n-3 PUFA," Meat Science, vol. 55, no. 2, pp. 213-221, 2000.

[37] M. M. Selani, C. J. Contreras-Castillo, L. D. Shirahigue, C. R. Gallo, M. Plata-Oviedo, and N. D. Montes-Villanueva, "Wine industry residues extracts as natural antioxidants in raw and cooked chicken meat during frozen storage," Meat Science, vol. 88, no. 3, pp. 397-403, 2011.

[38] R. Gyawali, S. A. Hayek, and S. A. Ibrahim, "Plant extracts as antimicrobials in food products: mechanisms of action, extraction methods, and applications," in Handbook of Natural Antimicrobials for Food Safety and Quality, T. M. Taylor, Ed., Woodhead Publishing, Cambridge, UK, 2015.

[39] M. Sulbarán-Mora, E. Pérez-Pérez, and P. Vit, “Antibacterial activity of ethanolic extracts of pot-pollen produced by eight meliponine species from Venezuela," in Pot-Pollen in Stingless Bee Melittology, P. Vit, S. R. M. Pedro, and D. W. Roubik, Eds., pp. 391-399, Springer International Publishing, New York, NY, USA, 2018.

[40] M. N. Lani, T. A. Peng, Z. Suhaili, and Z. Hassan, "Microbiological evaluation on raw materials and food contact surfaces of 'keropok lekor' premises in Kuala Nerus, Terengganu and their prevalence of antibiotic resistant bacteria," Malaysian Applied Biology, vol. 46, no. 3, pp. 71-80, 2017.

[41] M. Vanitha, K. Dhanapal, and G. Vidya Sagar Reddy, "Quality changes in fish burger from Catla (Catla Catla) during refrigerated storage," Journal of Food Science and Technology, vol. 52, no. 3, pp. 1766-1771, 2015. 